\title{
Surgical outcomes of Laparoscopic Choledochal Cyst Excision and Roux-En-Y Hepaticojejunostomy in Children
}

\author{
Nguyen Thanh Xuan ${ }^{1}$, Ho Huu Thien ${ }^{1}$, Pham Anh Vu ${ }^{2}$ Phan Hai Thanh${ }^{1}$, Dang Nhu Thanh ${ }^{1}$, Nguyen Du Vinh${ }^{1}$, \\ Nguyen Huu Son ${ }^{3 *}$, Pham Nhu Hiep ${ }^{1}$ \\ ${ }^{1}$ Department of Pediatric and Abdominal Emergency Surgery, Hue Central Hospital, Vietnam
}

${ }^{2}$ Department of Surgery, Hue University of Medicine and Pharmacy, Vietnam

${ }^{3}$ Pediatric Center, Hue Central Hospital, Vietnam

Received: May 27, 2019; Published: June 19, 2019

*Corresponding author: Nguyen Huu Son, Pediatric Center, Hue Central Hospital, 16 Le Loi street, Hue city, Vietnam

\begin{abstract}
Purpose: Laparoscopic cyst excision and Roux-en-Y hepaticojejunostomy is gaining popularity as a treatment for choledochal cyst in children. The aim of this study is to determine the feasible and safe of the laparoscopic excision with Roux-en-Y hepaticojejunostomy and evaluate the short-term outcomes after treatment for children with choledochal cyst.

Methods: A prospectively of 51 consecutive pediatric patients undergoing laparoscopic choledochal cyst excision and Roux-en-Y hepaticojejunostomy performed by one surgeon cysts at Hue Central Hospital from June 2012 to December 2017 was studied.

Results: The mean operative time was $214.7 \pm 67.95$ minutes (range, 100 360 minutes), including the time for intraoperative cholangiography. There were two children requiring blood transfusion. Time to first flatus was $40.35 \pm 28.55$ hours in average. The mean time to drain removal was $2.89 \pm 1.02$ days. Mean postoperative hospital stay was $9.31 \pm 3.43$ days. $6 / 51$ cases having early complications, including 2 cases of pancreatitis and 4 cases of bile leakage. Most of cases (90.5\%) were classified as good after 10 days to 3 months of follow-up.

Conclusion: Laparoscopic choledochal cyst excision and Roux-en-Y hepaticojejunostomy was feasible and safe in children. The shortterm outcomes were good in most cases.
\end{abstract}

Keywords: Laparoscopic excision, Roux-en-Y hepaticojejunostomy, choledochal cyst, children.

\section{Introduction}

Choledochal cysts are a rare congenital cystic dilation of the biliary tract, first described by Vater and Ezler in 1723. They present primarily in female infants and young children and are more prevalent in East Asian populations. although benign, choledochal cysts can be associated with serious complications including malignant transformation, cholangitis, pancreatitis, and cholelithiasis [1,2]. Hence, complete surgical excision of the choledochal cyst and enterobiliary reconstruction has been recommended as the standard treatment.

Choledochal cyst excision and biliary enteric reconstruction constitute the best therapy for choledochal cyst [3]. Comparing with open procedure, laparoscopic procedure has been proven to have shorter hospital stay and lower morbidity of anastomotic stenosis, bile leakage, intrahepatic stone formation, cholangitis, pancreatic leak, intestinal obstruction, and re-operation $[4,5]$. Thus, as a safe, efficacious, and minimally invasive procedure, laparoscopic cyst excision and Roux-en-Y hepaticojejunostomy has become a common procedure for pediatric choledochal cyst in many medical centers [6]. With increased familiarity with the laparoscopic anatomy of the biliary tract and advances in minimally invasive techniques, surgeons have ventured further to operate on technically difficult cases such as choledochal cyst that were until recently managed by laparotomy [7]. Our preliminary result shows that laparoscopic excision of choledochal cyst and Roux-en-Y hepaticojejunostomy is effectiveness in pediatric patients [8]. The purpose of this study was to determine the feasible and safe of the laparoscopic excision with Roux-en-Y hepaticojejunostomy and evaluate the short-term outcomes after treatment for children with choledochal cyst. 


\section{Methods}

\section{Patients}

A prospective study involving 51 pediatric patients diagnosed with choledochal cysts at Hue Central Hospital from June 2012 to December 2017. All patients underwent laparoscopic choledochal cyst excision and Roux-en-Y hepaticojejunostomy. all procedures were performed by the same surgery team. This study was approved by the ethics committee review board of our hospital. The variables investigated were demographic information of all patients, operative details and outcomes such as operation time, intraoperative blood transfusion, postoperative time to first flatus and postoperative hospital stay, and postoperative complications.

\section{Operative Technique}

The procedure of laparoscopic choledochal cyst excision is summarized below:

i. Under general anesthesia, the patient was intubated and placed in reverse Trendelenburg position.

ii. Four-site procedure was used as the trocars were located at middle of the umbilicus, right hypochondrium, right side of the abdomen, and left hypochondrium, respectively.

iii. A monopolar electrocautery hook was used to dissect the choledochal cyst and the gallbladder. The cyst was dissected down to the distal tapered end of the common bile duct, and it was then ligated. The upper part of the cyst was further dissected up to the common hepatic duct and then removed at this level. When severe adhesion around the cyst was encountered, bipolar coagulation was used for dissecting.

iv. A Roux-en-Y anastomosis was constructed by exteriorization of the small bowel via the enlarged umbilical trocar port. a retrocolic end-to-side hepaticojejunostomy was carried out laparoscopically. To minimize the biliary contamination of peritoneum, our procedure was modified later in the series by completing the jejunojejunostomy before the cyst excision.

v. Draining tube was indicated only in selected cases.

vi. When common hepatic duct stenosis was encountered in the Todani-IV a type cases, the stenosis was resected or a ductoplasty was performed by a longitudinal incision on the anterior wall and followed by additional cholangioenterostomy.

\section{Postoperative Management and Follow-up of Patients}

Patients usually started a liquid diet on postoperative day 1. Jackson-Pratt drains were removed if ultrasound that were performed on postoperative day 4 showed no evidence of abnormal fluid collection. Patients revisited the outpatient department 2 weeks after discharge and were followed up at 3 months to monitor postoperative complications. For follow-up, a routine complete blood count, liver function test, and ultrasound or CT were performed to evaluate complications, such as pancreatitis, cholangitis, choledocholithiasis, or malignancy.

Clinical outcome was determined according to the Terblanche classification [9] grade I, no biliary symptoms; grade II, transitory symptoms and no current symptoms; grade III, biliary symptoms requiring medical therapy; and grade IV, recurrent biliary symptoms requiring correction or related to death. Terblanche class IV constituted a poor result. Terblanche I, II, and III constituted a clinical success with excellent, good, and fair results, respectively.

\section{Data Analysis}

For a descriptive analysis, the frequency or the mean and standard deviation were calculated for each variable. For other continuous variables, independent sample t-tests were applied to compare the data from the children and adult groups. Their respective $\mathrm{p}$-values and corresponding confidence intervals were provided by SPSS Version 18.0 (SPSS Inc., Chicago, Illinois, USA). The statistical significance was set at $\mathrm{p}<0.05$.

\section{Results}

Table 1: Patient characteristics.

\begin{tabular}{|c|c|}
\hline Variables & All Patients $(\mathbf{n = 5 1})$ \\
\hline Gender & \\
\hline Female & $41(80.4 \%)$ \\
\hline Male & $10(19.6 \%)$ \\
\hline Age (mean, range) & 3.55 years $(2.5$ months $\sim 15$ years $)$ \\
\hline Operative time (mins, range) & $214.7 \pm 67.95(100 \sim 360)$ \\
\hline
\end{tabular}

Table 2: Surgical outcomes of laparoscopic choledochal cyst excision and Roux-en-Y hepaticojejunostomy.

\begin{tabular}{|c|c|}
\hline Variables & All Patients (n=51) \\
\hline $\begin{array}{c}\text { Number of patient requiring blood } \\
\text { transusion }\end{array}$ & 2 \\
\hline Blood transfusion volume & $125.0 \pm 35.36$ \\
\hline Time to first flatus (hours) & $40.35 \pm 28.55$ \\
\hline Time to drain removal (days) & $2.89 \pm 1.02$ \\
\hline Hospital stay (days) & $9.31 \pm 3.43$ \\
\hline Complications & 4 \\
\hline Biliary leakage & 0 \\
\hline Fluid collection & 2 \\
\hline Pancreatitis & $\mathrm{n}=42$ (9 patients were lost to \\
\hline follow-up)
\end{tabular}

Forty-one patients were females and 10 were males. The mean age at the time of surgery was 3.55 years (range, 2.5 months $\sim 15$ years). The mean operative time was $214.7 \pm 67.95$ 
minutes (range, 100 360 minutes), including the time for intraoperative cholangiography. The patient characteristics and the operative features were seen in Table 1.

Table 2 shows the surgical outcomes of laparoscopic choledochal cyst excision and Roux-en-Y hepaticojejunostomy. There were two children requiring blood transfusion with the total volume of packed red blood cells of $125.0 \pm 35.36 \mathrm{ml}$. Time to first flatus was $40.35 \pm 28.55$ hours in average. The mean time to drain removal was $2.89 \pm 1.02$ days. Mean postoperative hospital stay was $9.31 \pm 3.43$ days. $6 / 51$ cases having early complications, including 2 cases of pancreatitis and 4 cases of bile leakage. Conservative treatment was initially implemented which resulted in complete resolution in 5 cases. Re operative was finally required in 1 case with persistent bile leakage. Most of cases were classified as good after 10 days to 3 months of follow-up.

\section{Discussion}

Choledochal cyst is a rare congenital anomaly of the biliary system that commonly affects the Asian population [10]. The estimated incidence of choledochal cyst and anomalous pancreatobiliary ductal union is $0.3 \%$ and $4.1 \%$, respectively, according to a large, multicenter study [11]. The clinical presentation of choledochal cyst differs from children to adults. In adults, this disease entity can manifest cholangitis, pancreatitis, choledocholithiasis, or biliary malignancy, such as cholangiocarcinoma or gallbladder cancer [11]. Complete excision of the cyst is mandatory because of the risk of developing complications or malignancies.

With growing interest in cosmetics, laparoscopic approaches in hepatobiliary surgery have become inevitable. Laparoscopic hepaticojejunostomy anastomosis still remains one of the most sophisticated and challenging surgeries to date [12]. Since the first report of laparoscopic choledochal cyst excision in 1995 [13] studies regarding this approach have reported that laparoscopic surgery is safe and feasible in the treatment of choledochal cysts.

Choledochal cyst is characterized by its remarkably higher incidence in the female patients together with the regional preference. In this study also, we found more cases of female patients, the female/male ratio in our study was $4.0 / 1$. This was similar to other studies. Sheng Q (2017) showed a female/male ratio of $15 / 3=5$. [14]. In the study of Liu Y et al. [5], the female/ male ratio was $29 / 6=4.83 .5$ Since choledochal cyst is more common in female, the aesthetic advantages of laparoscopic procedure are more relevant. Patient's age ranged from 2.5 months to 15 years (Table 1 ). The mean age was 3.55 years. The results of our study were similar to other studies. Huang CS et al. [15] reported 101 cases of choledochal cysts in which 42 cases were children (41.6\%) and 59 cases were adults (58.4\%). The mean age was 8.9 years 3.7 years for children [15].

Operative time ranged from 100 to 320 mins. Mean operative time was $214.7 \pm 67.95$ mins. Minimizing operative time and maintaining outcomes at the same time has always been a challenge to surgeons, especially in young children and infants. If surgery is too lengthy, comorbidity rate will increase. To shorten operative time, multiple factors are required including competent skills of surgeon, assistants and nurses, close coordination with anesthesiologists and adapted instruments. Therefore, operative time in the beginning of the learning curve of laparoscopic procedure is longer. Operative time of laparoscopic procedure was also longer compared to open procedure in recent studies. Our operative time was comparable to the study of Liem NT (2012) with 400 patients, the operative time in hepatoduodenal anastomosis group was 164.8 mins, and in hepatojejunal anastomosis group was 220 mins [16]. According to Liu Y et al. [5], mean operative time of laparoscopic procedure was 249 mins, longer than open procedure with mean operative time of 132 mins [5].

One of the complications of laparoscopic choledochal cyst excision is bleeding requiring intraoperative blood transfusion. Liem NT (2012) reported four cases with bleeding requiring intraoperative blood transfusion, three cases with transection of both hepatic ducts and one case with right hepatic duct perforation [16]. Tang ST et al. [17] noted 8 cases requiring intraoperative blood transfusion.

Regarding the early postoperative complications, we noted 6/51 cases having early complications, including 2 cases of pancreatitis and 4 cases of bile leakage. Conservative treatment was initially implemented which resulted in complete resolution in 5 cases. Re operative was finally required in 1 case with persistent bile leakage. Re operative was finally required in 1 case with persistent bile leakage. Ono et al. [18] reported liver dysfunction, dilatation of intrahepatic bile ducts, recurrent abdominal pain, and biliary tract malignancy as long-term complications after choledochal cyst excision and hepaticojejunostomy. The laparoscopic approach can magnify the operative view, which may assist in dissecting the whole choledochal cyst without a remnant duct, and in anastomosis. Liuming H (2011) reported 1 case of postoperative bile leakage in a study of 39 patients [19]. In a study of acker SN (2013), the rate of bile leakage was $1.6 \%$. Pancreatitis was a relatively rare postoperative complication after choledochal cyst excision. Preoperative pancreatitis might be an important risk factor predisposing the patient to postoperative pancreatitis [20]. Compared to other studies, the rates of early complications of our study was low.

Several tips were suggested by some authors to reduce the rate of bile leakage. Firstly, electrical dissection should not be overused and over-dissecting the anterior wall of common hepatic duct should also be avoided. Secondly, good laparoscopic suture technique should be practiced. Thirdly, bowel loop with good arterial arcade with sufficient length should be chosen to construct a tension free anastomosis. Finally, the anastomosis should be carefully checked before the end of the operation. 
Other reported complication including incisional fluid collection, pancreatic fistulas and early adhesive intestinal obstruction was not noted in our study.

Our study contains some limitations. Firstly, the sample size was small, and the follow-up period was short (within 3 months). Secondly, there was no control group to compare such as open surgery to see the efficiency of laparoscopic choledochal cyst excision and Roux-en-Y hepaticojejunostomy in children.

\section{Conclusion}

Laparoscopic choledochal cyst excision and Roux-en-Y hepaticojejunostomy was feasible and safe in children. It could significantly improve in terms of operative time, overall postoperative complication rate, and the length of hospital stay. The short-term outcomes were good in most cases.

\section{Acknowledgment}

The authors are grateful to Prof. Pham Nhu Hiep - director of Hue Central Hospital; physicians, administrative staff at Department of Pediatric and Abdominal Emergency Surgery for allowing us to undertake this research.

\section{Author Contribution}

All authors participated in the study design, data collection, and literature search. Data was analyzed by NTX. NTX and NHS wrote the paper. all authors read and approved the final manuscript.

\section{Declarations}

i. Funding: No funding sources.

ii. Conflicts of interest: The authors declare no conflict of interest.

iii. Ethical approval: The study was approved by the Hospital Ethics Committee.

\section{References}

1. Soreide K, Korner H, Havnen J, Soreide JA (2004) Bile duct cysts in adults. Br J Surg 91(12): 1538-1548.

2. Tang W, Dong K, Liu G, Cui X, \& Zheng S (2015) The Clinical Characters of Congenital Choledochal Cysts in Perinatal Patients: A Retrospective Analysis in a Single Institution. Am J Perinatol 32(9): 853-858.

3. Kayaalp C, Soyer V, Ersan V, Aydin C, \& Karagul S (2016) Laparoscopic choledochal cyst excision and Roux-en-Y hepaticojejunostomy. Ulus Cerrahi Derg 32(2): 152-154.

4. Diao M, Li L, \& Cheng W (2011) Laparoscopic versus Open Roux-en-Y hepatojejunostomy for children with choledochal cysts: intermediate-term follow-up results. Surg Endosc 25(5): 1567-1573.
5. Liu Y, Yao X, Li S, Liu W, Liu L, et al. (2014) Comparison of therapeutic effects of laparoscopic and open operation for congenital choledochal cysts in adults. Gastroenterol Res Pract 2014: 670260.

6. Liem NT (2013) Laparoscopic surgery for choledochal cysts. J Hepatobiliary Pancreat Sci 20(5): 487-491.

7. Duan X, Mao X, Jiang B, Wu J (2015) Totally laparoscopic cyst excision and Roux-en-Y hepaticojejunostomy for choledochal cyst in adults: a single-institute experience of 5 years. Surg Laparosc Endosc Percutan Tech 25(2): e65-68.

8. Xuan NT, Hiep PN, Thien HH, Vu PA, Thanh PH, Khanh LD, et al. (2013) Laparoscopic excision of choledochal cyst in Hue Central Hospital. Vietnam Laparoscopic surgery and Endoscopy Journal 1(3): 22-25.

9. Terblanche J, Worthley CS, Spence RA, Krige JE (1990) High or low hepaticojejunostomy for bile duct strictures? Surgery 108(5): 828-834.

10. Wiseman K, Buczkowski AK, Chung SW, Francoeur J, Schaeffer D, et al. (2005) Epidemiology, presentation, diagnosis, and outcomes of choledochal cysts in adults in an urban environment. Am J Surg. 189(5): 527-531.

11. Lee SE, Jang JY, Lee YJ, Choi DW, Lee WJ, et al. (2011) Choledochal cyst and associated malignant tumors in adults: a multicenter survey in South Korea. Arch Surg 146(10): 1178-1184.

12. Choi SB, Choi SY (2016) Current status and future perspective of laparoscopic surgery in hepatobiliary disease. Kaohsiung J Med Sci 32(6): 281-291.

13. Farello GA, Cerofolini A, Rebonato M, Bergamaschi G, Ferrari C (1995) Congenital choledochal cyst: video-guided laparoscopic treatment. Surg Laparosc Endosc 5(5): 354-358.

14. Sheng Q, Lv Z, Xu W, Xiao X, Liu J, Wu Y (2017) Reoperation After Cyst Excision with Hepaticojejunostomy for Choledochal Cysts: Our Experience in 18 Cases. Med Sci Monit 23: 1371-1377.

15. Huang CS, Huang CC, and Chen DF (2010) Choledochal cysts: differences between paediatric and adult patients. J Gastrointest Surg 14(7): 1105-1110.

16. Liem NT, Pham HD, Dung le A, Son TN, Vu HM (2012) Early and intermediate outcomes of laparoscopic surgery for choledochal cysts with 400 patients. J Laparoendosc Adv Surg Tech A 22(6): 599-603.

17. Tang ST, Yang Y, Wang Y, Mao YZ, Li SW, et al. (2011) Laparoscopic choledochal cyst excision, hepaticojejunostomy, and extracorporeal Rouxen-Y anastomosis: a technical skill and intermediate-term report in 62 cases. Surg Endosc 25(2): 416-422.

18. Ono S, Fumino S, Shimadera S, Iwai N (2010) Long-term outcomes after hepaticojejunostomy for choledochal cyst: a 10- to 27-year follow-up. J Pediatr Surg. 2010 45(2): 376-378.

19. Liuming H, Hongwu Z, Gang L, Jun J, Wenying H, et al. (2011) The effect of laparoscopic excision vs open excision in children with choledochal cyst: a midterm follow-up study. J Pediatr Surg 46(4): 662-665.

20. Acker SN, Bruny JL, Narkewicz MR, Roach JP, Rogers A, et al. (2013) Preoperative imaging does not predict intrahepatic involvement in choledochal cysts. J Pediatr Surg 48(12): 2378-2382. 

$\begin{array}{ll}\text { (C) } & \begin{array}{l}\text { This work is licensed under Creative } \\ \text { Commons Attribution 4.0 Licens } \\ \text { DOI: 10.19080/OAJS.2019.10.555795 }\end{array}\end{array}$

\section{Your next submission with Juniper Publishers will reach you the below assets}

- Quality Editorial service

- Swift Peer Review

- Reprints availability

- E-prints Service

- Manuscript Podcast for convenient understanding

- Global attainment $\mathrm{f}$ or your research

- Manuscript accessibility in different formats ( Pdf, E-pub, Full Text, Audio)

- Unceasing customer service

Track the below URL for one-step submission https://juniperpublishers.com/online-submission.php 